\title{
Tryptic Digestion of Spectrin in Variants of Hereditary Elliptocytosis
}

\author{
T. Coetzer and S. S. ZAIL, Department of Haematology, School of Pathology \\ of the University of the Witwatersrand and the South African Institute \\ for Medical Research, Johannesburg, South Africa
}

\begin{abstract}
A B S T R A C T Spectrin, either in the form of unfractionated low ionic strength extracts of erythrocyte membranes or purified by chromatography on Sepharose $(\mathrm{CL}) 4 \mathrm{~B}$, was subjected to tryptic digestion at $0^{\circ} \mathrm{C}$. Four patients, each with a different variant of hereditary elliptocytosis, were studied. In one patient, whose erythrocytes showed significant fragmentation on heating to $45^{\circ} \mathrm{C}$, such preparations generated a remarkably different pattern of polypeptide fragments on tryptic digestion at low ionic strength. In this patient ${ }^{32} \mathrm{P}$ was released at a slower rate on tryptic digestion of labeled band 2, and an unusual ${ }^{32}$ P-labeled peptide fragment was also generated, in contrast to control preparations in which such a peptide could not be easily distinguished. There was increased susceptibility of this patient's spectrin to tryptic digestion at physiological ionic strength, but the qualitative pattern of polypeptide fragments was normal. Phosphorylation of spectrin by membrane protein kinase was markedly impaired in this patient, whereas phosphorylation of casein was unimpaired. However, the phosphorylation of spectrin in her intact erythrocytes was normal. Our findings suggest an abnormality of spectrin structure which we postulate is causally related to the predisposition to hemolysis in this patient, but do not distinguish whether this is a primary abnormality or a post-translational modification of the spectrin molecule. The other three patients showed normal tryptic digestion of spectrin.
\end{abstract}

\section{INTRODUCTION}

Hereditary elliptocytosis $(\mathrm{HE})^{1}$ is a relatively common disorder inherited normally in dominant fashion with

Address reprint requests to Dr. Zail, Department of Haematology, South African Institute for Medical Research, Box 1038, Johannesburg, 2000, South Africa.

Received for publication 20 August 1980 and in revised form 21 November 1980.

${ }^{1}$ Abbreviations used in this paper: $\mathrm{HE}$, hereditary elliptocytosis; HPP, hereditary pyropoikilocytosis; SDS-PAGE, sodium dodecyl sulfate-polyacrylamide gel electrophoresis; TPCK, L-1-tosyl-amido-2-phenylethyl chloromethyl ketone. complete penetrance. The clinical, genetic, and biochemical features of this disorder and of a closely related disease, hereditary pyropoikilocytosis (HPP), have been recently reviewed by Lux and Wolfe (1), who have delineated at least six clinical variants of $\mathrm{HE}$.

Both conditions appear to be due to a disorder of the erythrocyte membrane cytoskeletal network, which consists of spectrin, actin, bands 4.1 and 2.1, and a subcomponent of band 3 , since the HE and HPP ghost, as well as the cytoskeleton, replicate the erythrocyte morphology (2). In some families with $\mathrm{HE}$, spectrin is qualitatively abnormal as determined by abnormal heat sensitivity (2), but it is not known whether this reflects a primary molecular abnormality of spectrin or how such an abnormality could lead to an elliptocytic shape (1). Evidence that HPP erythrocytes also have a defect in spectrin was presented by Walter et al. (3), who found that spectrin phosphorylation by erythrocyte membrane protein kinase was markedly decreased in HPP ghosts, but was normal with exogenous substrates such as casein. However, they were unable to demonstrate any abnormality of spectrin using sensitive immunological techniques. More recently, Chang et al. (4), using circular dichroism criteria, found that spectrin purified from HPP ghosts had a greater loss of $\alpha$-helical structure on heating between $25^{\circ}$ and $44^{\circ} \mathrm{C}$ than normal, again suggesting an abnormality of spectrin in HPP.

In the present study we report findings in four unrelated patients with different variants of hereditary elliptocytosis. In one subject, a structural defect in spectrin was detected using mild tryptic digestion at low temperatures. This patient was originally reported by Gomperts et al. (5) as a case of hemolytic anemia due to hereditary elliptocytosis. Erythrocyte membrane protein abnormalities were detected in this patient using acetic acid extracts of ghosts which were separated by urea-starch gel electrophoresis (5). However, the exact relationship of these findings to current concepts of membrane protein structure based on sodium dodecyl sulphate-polyacrylamide gel electrophoresis (SDS-PAGE) is unknown, and have not been pursued in 
the present study. This patient has since been found to have significant budding and fragmentation of her erythrocytes on heating to $45^{\circ} \mathrm{C}$, but the budding is not as pronounced as is found in HPP in which more extensive fragmentation and sphering of erythrocytes occur at this temperature. Although she clearly has marked elliptocytosis, a few other features make it difficult to classify her as one of the usual variants of $\mathrm{HE}$. The other three $\mathrm{HE}$ variants included a black infant with probable transient poikilocytosis and pyknocytosis and abnormal thermal sensitivity, a white adult with mild HE and no hemolysis, and a white adult with mild $\mathrm{HE}$ and sporadic hemolysis. None of these patients had a detectable abnormality of spectrin on tryptic digestion.

\section{METHODS}

Subject C.G. This patient is the propositus described by Gomperts et al. (5). Hematologic data on her and her family remain essentially unchanged. In summary, the major hematological features of C.G. are those of a splenectomized white female with a well-compensated hemolytic anemia (hemoglobin, 14- $14.5 \mathrm{~g} / 100 \mathrm{ml}$; mean corpuscular volume, $82 \mathrm{fl}$; reticulocyte count, 6-10\%), increased autohemolysis corrected by glucose, increased osmotic fragility, and predominant elliptocytosis on the peripheral smear. However, many cells show significant budding and poikilocytosis (Fig. $1 a$ ). Incubation of the patient's heparinized venous blood at $45^{\circ} \mathrm{C}$ for $15 \mathrm{~min}$ results in striking membrane budding and cell fragmentation on phase-contrast microscopy of cells fixed in $1 \%$ glutaraldehyde (Fig. $1 b$ ) and also on Wright's staining of a blood smear (Fig. 1c). In contrast, normal cells show no discernable change (Fig. $1 d, e$ ). An identical result was obtained with the propositus' similarly affected sibling. On heating C.G's erythrocytes at $1^{\circ} \mathrm{C}$ increments up to $49^{\circ} \mathrm{C}$, progressive fragmentation and sphering of her erythrocytes occurred. Both the father and the mother were found to be hematologically normal, although the

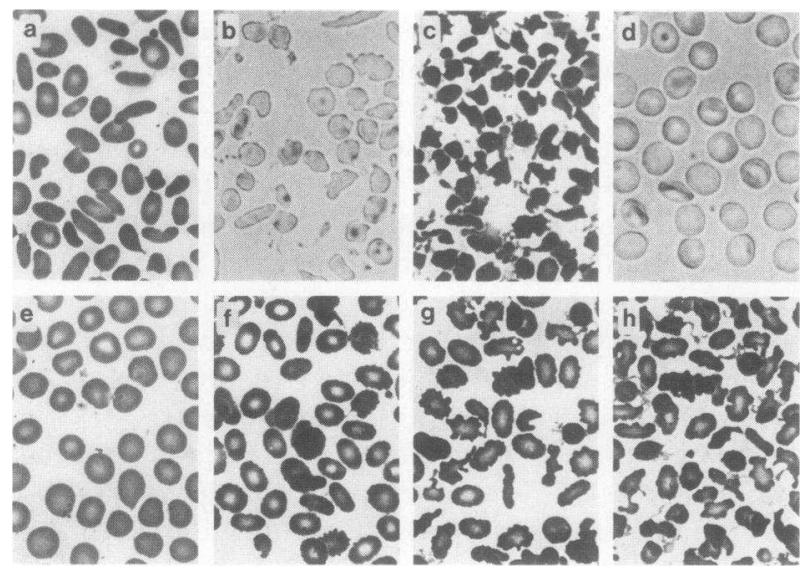

Figure 1 Fresh peripheral blood smear of C.G. (a) phase photomicrograph (b) and peripheral smear (c) of erythrocytes of C.G. heated for $15 \mathrm{~min}$ at $45^{\circ} \mathrm{C}$; phase photomicrograph (d) and peripheral smear (e) of erythrocytes of control subject heated for $15 \mathrm{~min}$ at $45^{\circ} \mathrm{C}$; fresh peripheral smear of erythrocytes of T.M. (f); peripheral smear of erythrocytes of T.M. heated for $15 \mathrm{~min}$ at $45^{\circ} \mathrm{C}(\mathrm{g})$ and $46^{\circ} \mathrm{C}(\mathrm{h})$. defect is thought to be transmitted by the father, as he has a splenectomized sister with a compensated hemolytic anemia (reticulocyte count $8 \%$ ) characterized primarily by spherocytosis and very mild elliptocytosis. The latter patient's erythrocytes, however, do not show any budding when heated to $45^{\circ} \mathrm{C}$ or $46^{\circ} \mathrm{C}$.

Subject T.M. This patient is a black child aged $11 \mathrm{mo}$. The detailed clinical and hematological features will be described elsewhere ${ }^{2}$ and in summary are as follows: splenomegaly, 2-3 $\mathrm{cm}$; hemoglobin, $10.0 \mathrm{~g} / 100 \mathrm{ml}$; reticulocyte count, $6 \%$; predominant elliptocytosis with erythrocyte budding and poikilocytosis on peripheral blood smear (Fig. 1 f); marked erythrocyte fragmentation on heating to $45^{\circ} \mathrm{C}$ (Fig. $\mathrm{lg}$ ), which was accentuated at $46^{\circ} \mathrm{C}$ (Fig. $\mathrm{l} h$ ) and showed progressive fragmentation and sphering up to $49^{\circ} \mathrm{C}$. The osmotic fragility was normal and autohemolysis was markedly increased. There are no siblings, and only the mother was available for study. She was hematologically normal. T.M. probably represents a case of mild $\mathrm{HE}$ with transient poikilocytosis and pyknocytosis in infancy as his peripheral blood morphology has shown progressive elliptocytic change since early infancy.

Subject R.L. This white female, aged $40 \mathrm{yr}$, was found to have an ongoing hemolytic anemia after hospitalization for a urinary tract infection in May 1979. Erythrocyte indices before splenectomy (April 1980) were hemoglobin, 8.2-11.8 g/100 ml; mean corpuscular volume, 79-84 $\mathrm{fl}$; reticulocyte count, 5.0$11.5 \%$. Peripheral blood morphology showed striking elliptocytosis and erythrocyte budding, very similar to that seen in C.G. above. Osmotic fragility and autohemolysis were normal. The ${ }^{51} \mathrm{Cr}$ half-life was $16 \mathrm{~d}$, and surface counting showed predominant splenic sequestration of ${ }^{51} \mathrm{Cr}$-labeled erythrocytes. Following splenectomy the hemoglobin has varied between 13.5 and $14.3 \mathrm{~g} / 100 \mathrm{ml}$ and reticulocyte count between 1.5 and $1.8 \%$. Incubation of her erythrocytes at $45-49^{\circ} \mathrm{C}$ both before and after splenectomy shows only mild fragmentation, commencing at $48^{\circ} \mathrm{C}$ with almost complete sphering at $49^{\circ} \mathrm{C}$. The parents of this patient are deceased, and examination of her three children revealed no hemotological abnormality. She represents a case of mild $\mathrm{HE}$ with sporadic hemolysis.

Subject J.E. This 19-yr-old white female medical student shows prominent elliptocytosis but no budding on the peripheral smear, with a hemoglobin of $14.0 \mathrm{~g} / 100 \mathrm{ml}$ and a reticulocyte count of $1 \%$. Osmostic fragility and autohemolysis are normal. Heat stability studies of her erythrocytes are similar to those of subject R.L. Her mother has a similar peripheral blood morphology. This patient represents classical mild HE with no hemolysis.

Materials. $\quad \gamma-\left[{ }^{32} \mathrm{P}\right] \mathrm{ATP}$ and $\left[{ }^{32} \mathrm{P}\right]$ orthophosphoric acid, carrier-free in $0.02 \mathrm{~N} \mathrm{HCl}$, were purchased from Radiochemical Centre, Amersham, England. Trypsin treated with L-1tosyl-amido-2-phenylethyl chloromethyl ketone (TPCK:trypsin) was from Worthington Biochemical Corp., Freehold, N. J. Sepharose (CL)4B was from Pharmacia Fine Chemicals, Uppsala, Sweden. Casein was from E. Merck, Darmstadt, West Germany.

Preparation of spectrin for tryptic digestion. Heparinized venous blood was collected on ice and processed within $1 \mathrm{~h}$. Membranes were prepared by hypotonic lysis of packed erythrocytes in $10 \mathrm{mM}$ Tris- $\mathrm{HCl}$ buffer, $\mathrm{pH} 7.6$, containing $1.0 \mathrm{mM}$ EDTA as previously described (6). Spectrin was extracted by suspending membranes $(2-3 \mathrm{mg}$ membrane protein $/ \mathrm{ml}$ ) in 0.1 mM EDTA, pH 7. 6, for $10 \mathrm{~min}$ at $37^{\circ} \mathrm{C}$, or by dialysis against

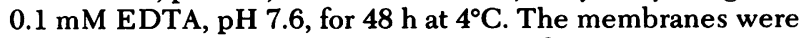
removed by centrifugation at $150,000 \mathrm{~g}$ for $20 \mathrm{~min}$. In most experiments this extract was used without further purification. In one experiment spectrin was purified by gel filtration of $37^{\circ}$

${ }^{2}$ Macdougall, L. Manuscript in preparation. 
and $4^{\circ} \mathrm{C}$ low ionic strength membrane extracts on $1.0 \times 60-\mathrm{cm}$ Sepharose (CL) $4 \mathrm{~B}$ columns equilibrated at $4^{\circ} \mathrm{C}$ with $5 \mathrm{mM}$ sodium phosphate, $1 \mathrm{mM}$ EDTA, $1 \mathrm{mM}$ dithiothreitol, and 0.5 $\mathrm{mM}$ sodium azide, $\mathrm{pH}$ 8.0. The flow rate was $15 \mathrm{ml} / \mathrm{h}$, and fractions of $0.8 \mathrm{ml}$ were collected and absorbance monitored continuously at $280 \mathrm{~nm}$. Three peaks of protein were resolved, the middle peak containing only spectrin as determined by SDS-PAGE.

${ }^{32} P$-Phosphorylation of spectrin in erythrocytes. Equilibration of erythrocytes with [ $\left.{ }^{32} \mathrm{P}\right]$ phosphate was done by the method of Bennett and Branton (7) except that prior depletion of the cells of ATP was omitted. The cells were incubated for $15 \mathrm{~h}$ at $37^{\circ} \mathrm{C}$ and then washed twice in ice-cold $310 \operatorname{mos} \mathrm{M}$ $\mathrm{NaCl}$; membranes and spectrin extracts were prepared as above.

Tryptic digestion of spectrin. The method was essentially that of Anderson (8). In different experiments, unfractionated spectrin extracts or purified spectrin was made $5 \mathrm{mM}, 10 \mathrm{mM}$, or $150 \mathrm{mM}$ in $\mathrm{NH}_{4} \mathrm{HCO}_{3}, \mathrm{pH} 7.8$, on ice; and TPCK:trypsin was added at 1:200 wt/wt. Aliquots were removed at intervals up to $24 \mathrm{~h}$, made $1 \%$ in SDS, $5 \%$ in $\beta$-mercaptoethanol, and heated for $3 \mathrm{~min}$ in a boiling water bath.

Gel electrophoresis. Analytical SDS-PAGE on tube and slab gels (3\% acrylamide) was performed using the conditions of Fairbanks et al. (9). $10 \mu \mathrm{g}$ of protein was loaded on all gels in which spectrin digests were fractionated. Molecular weights were determined using as markers the molecular weights assigned to erythrocyte membrane proteins by Steck (10). Bands were numbered 1-7 according to the convention of Steck (10). ${ }^{32} \mathrm{P}$-labeled gels were dried on filter paper using a Bio-Rad gel drier (Bio-Rad Laboratories, Richmond, Calif.), and radioautographed on Kodak X-Omat RP x-ray film (Eastman Kodak Co., Rochester, N. Y.). Protein concentrations were determined by the method of Lowry et al. (11) using bovine serum albumin as standard.

Assay of erythrocyte membrane spectrin kinase and casein kinase activity. Phosphorylation of spectrin (band 2) of isolated membranes by $\gamma-\left[{ }^{32} \mathrm{P}\right] \mathrm{ATP}$ was performed using the conditions decribed by Beutler et al. (12). Phosphorylation of casein was determined under the same incubation conditions for phosphorylation of spectrin, using $2 \mathrm{mg} / \mathrm{ml}$ casein and terminating the reaction at $10 \mathrm{~min}$ by the method of Corbin and Reimann (13). A correction was made for phosphorylation of endogenous erythrocyte membrane proteins.

Spectrin extractability. Spectrin extractability of erythrocyte membranes at $4^{\circ} \mathrm{C}$ was determined as previously described (6).

\section{RESULTS}

SDS-PAGE of HE erythrocyte membranes. Erythrocyte membrane proteins of subject C.G. (Fig. 2, gel b) are essentially similar to the control (Fig. 2, gel a), except for a slight decrease in the proportion of spectrin and increased binding of hemoglobin. Membranes of T.M. (Fig. 2, gel c) are similar to the control, except for a marked increase in bound hemoglobin. Increased binding of hemoglobin has, however, not been a constant finding in these membranes. SDS-PAGE of erythrocyte membrane proteins of R.L. and J.E. are identical to control preparations (not shown).

Tryptic digestion of unlabeled spectrin at low salt concentration ( $5 \mathrm{mM} \mathrm{NH}_{4} \mathrm{HCO}_{3}$ ). Low ionic strength extraction of membranes at $4^{\circ} \mathrm{C}$ yields spectrin with lesser amounts of actin and band 4.1 (Fig. 3, gel $a$ and b).

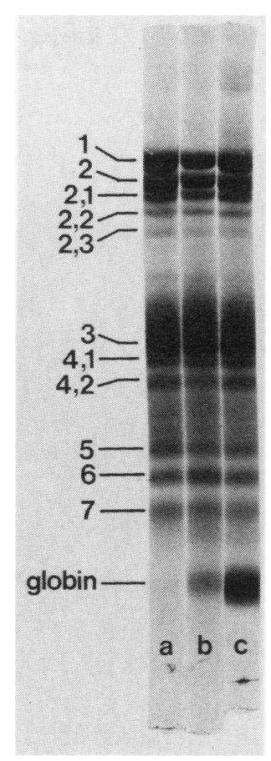

FIGURE 2 SDS-PAGE of freshly prepared erythrocyte membrane proteins: control (gel a), subject C.G. (gel b); subject T.M. (gel c). $40 \mu \mathrm{g}$ protein was applied to each gel.

In three separate experiments, tryptic digestion of such whole spectrin extracts at low salt concentrations for 2 , 5,15 , and $40 \mathrm{~min}$, and for $24 \mathrm{~h}$, yields a series of large polypeptides below band 2 in both the control and in subject C.G. Results of one experiment are shown in Fig. 3. The pattern of polypeptide fragments generated at the various time intervals is distinctly different in the control and subject C.G. In the control after 2 min digestion, one or more tryptic fragments, which cannot be clearly resolved, with an apparent molecular weight of 200-210,000 are generated just below band 2 (Fig. 3, gel c). Fainter bands are seen with apparent molecular weights of 190,000, 145,000 and 126,000. A similar pattern is seen at $5 \mathrm{~min}$ in which some digestion of both bands 1 and 2 can also be discerned. The pattern is further accentuated at 15 and $40 \mathrm{~min}$ (gels $\mathrm{g}$ and i), when tryptic fragments with molecular weights of $\sim 200,000,190,000$ and 180,000 become clearly visible as well as several fragments with molecular weights ranging between 126,000 and 54,000 . The latter lower molecular weight fragments are even more pronounced at $24 \mathrm{~h}$ (gel k), and there is complete disappearance of bands 1 and 2 with only traces of the fragments of molecular weight between 190 and 210,000 . In contrast, in patient C.G. at 2 and $5 \mathrm{~min}$ (gels $\mathrm{d}$ and $\mathrm{f}$ ), the large fragment or fragments with molecular weight between 200 and 210,000 are generated in only trace quantities. Band 2 appears to be resistant to tryptic digestion, whereas band 1 shows some diminution in staining intensity similar to that of the control. Fragments of molecular weight 145,000 and 126,000 are also generated and are more prominent than in the control. At 15 


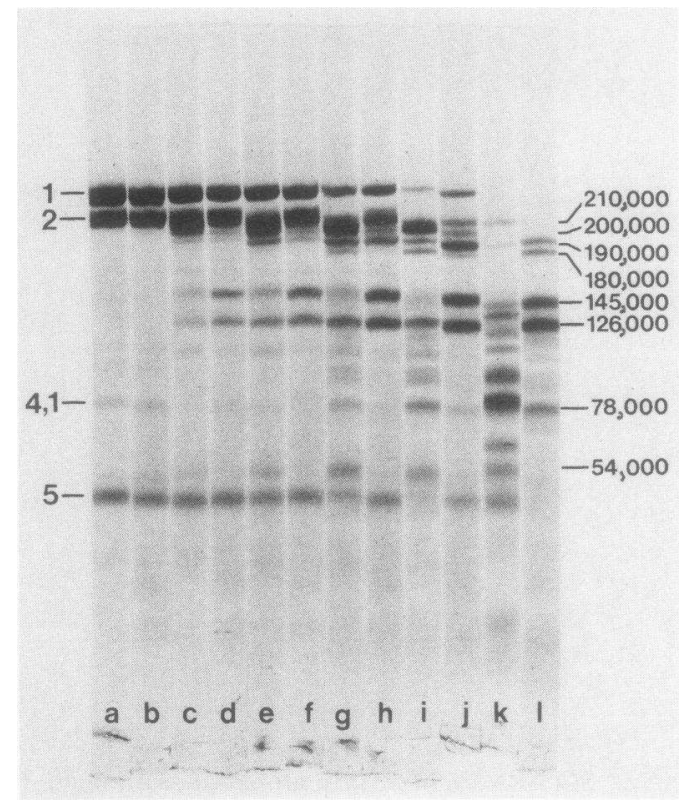

FIGURE 3 SDS-PAGE of tryptic peptides generated at low salt concentration $\left(5 \mathrm{mM} \mathrm{NH} \mathrm{HCO}_{3}\right)$. Spectrin extracts were obtained by low ionic strength extraction of isolated membranes at $4^{\circ} \mathrm{C}$. Spectrin from control membranes digested for $0,2,5,15$, and $40 \mathrm{~min}$, and for $24 \mathrm{~h}$ (gels a, c, e, g, i, and $k$, respectively). Spectrin from membranes of subject C.G. digested for $0,2,5,15$, and $40 \mathrm{~min}$, and for $24 \mathrm{~h}$ (gels b, $d, f, h, j$, and $l$, respectively). The molecular weights of some of the tryptic fragments are shown on the right-hand side of the figure.

min in patient C.G. (gel h), some digestion of band 2 is apparent, which becomes more pronounced at $40 \mathrm{~min}$ (gel j) with generation of fragments of molecular weight $210,000,200,000,190,000$, and 180,000 , and two major fragments of molecular weight 145,000 and 126,000 . In contrast to the control, fragments below molecular weight 126,000 are hardly discernible. At $24 \mathrm{~h}$, the tryptic fragments seen in patient C.G. (gel l) are also markedly different to the control. As at $40 \mathrm{~min}$, the major fragments have molecular weights of 145,000 and 126,000 . These appear to be resistant to further tryptic digestion, as evidenced by a marked paucity of fragments below a molecular weight of 126,000 , with the exception of one with a molecular weight of 78,000. A further difference between the control and C.G. is an apparent resistance of band 5 to tryptic digestion in C.G., which is manifest particularly at 15 and $40 \mathrm{~min}$ (gels $h$ and $j$ ). This difference is, however, due to an unusual susceptibility of band 5 in the control (one of the authors) to tryptic digestion. In a different control, depicted in Fig. 4, band 5 does not undergo complete digestion, which is the usual finding in control membrane extracts.

Tryptic digests at $0^{\circ} \mathrm{C}$ of unfractionated spectrin extracts obtained after incubating membranes of C.G. at

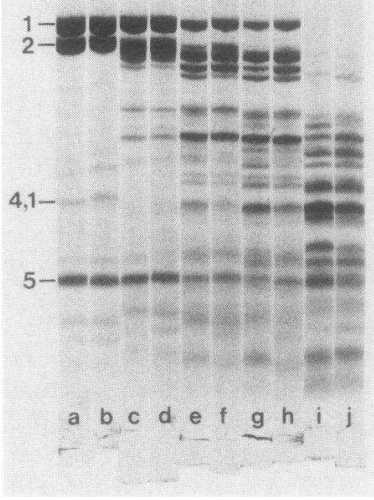

FIGURE 4 SDS-PAGE of tryptic peptides generated at low salt concentration $\left(5 \mathrm{mM} \mathrm{NH} \mathrm{HCO}_{3}\right)$. Spectrin extracts were obtained by low ionic strength extraction of isolated membranes at $37^{\circ} \mathrm{C}$. Spectrin from control membranes digested for $0,2,15$, and $40 \mathrm{~min}$, and for 24 hours (gels a, c, e, g, and $i$, respectively). Spectrin from membranes of subject T.M. digested for $0,2,15$, and $40 \mathrm{~min}$, and for $24 \mathrm{~h}$ (gels b, d, f, h, and $\mathbf{j}$, respectively).

$37^{\circ} \mathrm{C}$ were almost identical to those obtained with $4^{\circ} \mathrm{C}$ extracts. A similarly affected sister of C.G. showed an identical pattern on tryptic digests of unfractionated spectrin extracts. Furthermore, tryptic digests of spectrin purified by column chromatography of $4^{\circ} \mathrm{C}$ membrane extracts or $37^{\circ} \mathrm{C}$ membrane extracts from subject C.G. showed the same patterns as unfractionated extracts (not shown). The possibility that the altered pattern of tryptic peptides seen in C.G. might be related to the young erythrocyte population was excluded by an experiment using spectrin obtained from membranes of a patient with hereditary spherocytosis (pre-splenectomy, reticulocyte count 5\%). Tryptic peptides in this subject were identical to the control.

Tryptic digests at various intervals of unfractionated spectrin extracts obtained after incubation at $37^{\circ} \mathrm{C}$ of membranes of subject T.M. are shown in Fig. 4. The pattern of fragments generated is essentially the same as the control. Similar results were obtained with $4^{\circ} \mathrm{C}$ extracts. In one experiment, tryptic peptides of spectrin generated at slightly higher salt concentration $(10 \mathrm{mM}$ $\mathrm{NH}_{4} \mathrm{HCO}_{3}$ ) were identical in T.M. and the control. Tryptic digests of spectrin extracts of R.L. and J.E. were also identical to controls (not shown).

In addition to the difference in the digestion of band 5 seen in various control preparations, other minor differences between different controls are also apparent, particularly the resistance of the tryptic peptide of molecular weight 145,000 to further digestion. In Fig. 3 , this peptide is almost completely digested at $40 \mathrm{~min}$ 
(gel i), whereas it is still apparent in a different control depicted in Fig. 4 (gel g). In all control digestions the intensity of staining of this peptide is markedly less than that of the peptide of molecular weight 126,000 . The same control preparation, however, shows very little variation in different digestions as does the digestion pattern of the spectrin of C.G.

Tryptic digestion of unlabeled spectrin at high salt concentration (150 $\mathrm{mM} \mathrm{NH} \mathrm{NHCO}_{3}$ ). Tryptic digest patterns at high salt concentration $\left(150 \mathrm{mM} \mathrm{NH}_{4} \mathrm{HCO}_{3}\right)$ of unfractionated spectrin extracts of a control and C.G. at various intervals are shown in Fig. 5. Such digestions yield a smaller number of peptides than those at low salt concentration, the major peptides released having molecular weights of 145,000 and 126,000. Although the qualitative pattern of tryptic peptides in the control and C.G. are identical at times up to $\mathbf{4 0} \mathrm{min}$, major quantitative differences are apparent, in that both bands 1 and 2 in C.G. are more susceptible to tryptic digestion, and the tryptic peptides of molecular weight 145,000 and 126,000 are markedly increased compared with the control. At $24 \mathrm{~h}$ the tryptic peptides generated appear identical. The same pattern is evident when different controls are used. Tryptic digest patterns of spectrin at high salt concentrations of patients T.M., R.L., and J.E. are identical to control spectrin preparations.

Tryptic digestion of ${ }^{32}$ P-labeled band 2 . Erythrocytes of patient C.G. and a control were incubated with

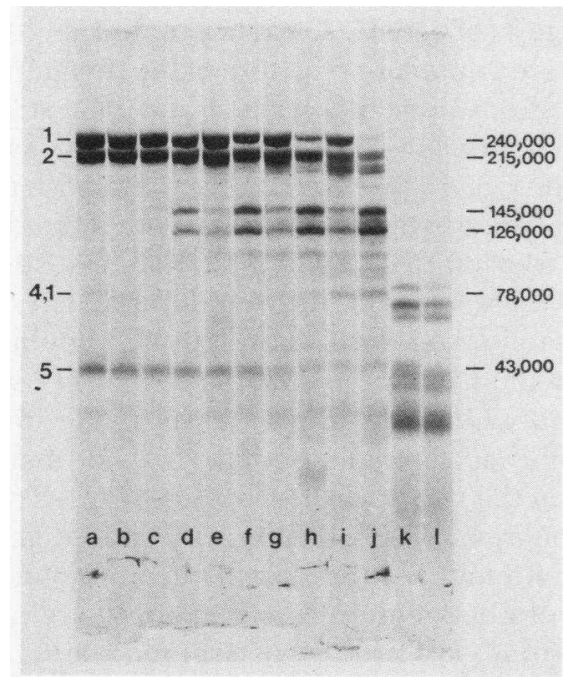

FIGURE 5 SDS-PAGE of tryptic peptides generated at high salt concentration $\left(150 \mathrm{mM} \mathrm{NH}_{4} \mathrm{HCO}_{3}\right)$. Spectrin extracts were obtained by low ionic strength extraction of isolated membranes at $4^{\circ} \mathrm{C}$. Spectrin from control membranes digested for $0,2,5,15$, and $40 \mathrm{~min}$, and for $24 \mathrm{~h}$ (gels a, c, e, g, i, and $k$, respectively). Spectrin from membranes of subject C.G. digested for $0,2,5,15$, and $40 \mathrm{~min}$, and for $24 \mathrm{~h}$ (gels b, d, f, $\mathrm{h}, \mathrm{j}$, and $\mathrm{l}$, respectively). The molecular weights of some of the tryptic fragments are shown on the right-hand side of the figure.
${ }^{32} \mathrm{PO}_{4}$ and unfractionated $4^{\circ} \mathrm{C}$ spectrin extracts were subjected to tryptic digestion for $2,5,15,40 \mathrm{~min}$, and for $24 \mathrm{~h}$. The tryptic fragments generated are shown in Fig. $6 \mathrm{~A}$ in a slab gel stained with coomassie blue. The pattern is essentially the same as Fig. 3, except that the resolution of some of the minor components is not as clear. Fig $6 \mathrm{~B}$ is the autoradiograph of the slab shown in Fig. 6A. Basal counts per minute in band 2 at $0 \mathrm{~min}$ in the control and subject C.G. (gels $a$ and $b$ ) are 1,184 and 1,280 . Because the same quantities of spectrin $(10 \mu \mathrm{g})$ were loaded on the gels, the specific activities of band 2 are almost identical in the control and in C.G., indicating that phosphorylation of spectrin in the intact erythrocytes of C.G. is normal. Counts per minute in band 2 in the control at $2,5,15$, and $40 \mathrm{~min}$, and at $24 \mathrm{~h}$ are 524 , 276,84 , undetectable, and undetectable, respectively, and in patient C.G. are $748,487,301,158$, and undetectable, respectively, indicating a slower rate of release of ${ }^{32} \mathrm{P}$ from labeled band 2 in subject C.G. Of some interest is the appearance of an unusual ${ }^{32} \mathrm{P}$-labeled tryptic fragment of approximate molecular weight 200,000 at $15 \mathrm{~min}$ in patient C.G., which is still discernible at $\mathbf{4 0} \mathrm{min}$ (gels $\mathrm{h}$ and $\mathrm{j}$, respectively). Similar findings were obtained using $37^{\circ} \mathrm{C}$ extracts of ${ }^{32} \mathrm{P}$ labeled membranes, except that the rate of loss of activity was more rapid in the control, with only $5 \%$ activity remaining at $5 \mathrm{~min}$.

An experiment using ${ }^{32} \mathrm{P}$-labeled spectrin of T.M.'s erythrocytes showed no difference in the rate of loss of ${ }^{32} \mathrm{P}$ when compared with a control (not shown). Experiments using ${ }^{32} \mathrm{P}$-labeled spectrin of R.L. and J.E.'s erythrocytes were not performed.

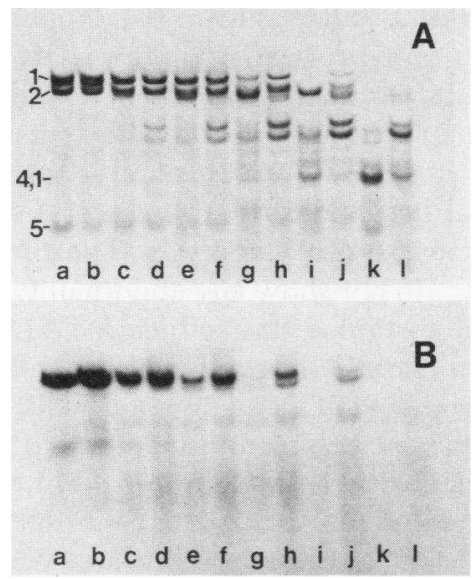

Figure 6 SDS-PAGE of tryptic peptides of ${ }^{32} \mathrm{P}$-phosphorylated spectrin. (A) Coomassie blue stain of spectrin digests from control membranes at $0,2,5,15$, and $40 \mathrm{~min}$, and at $24 \mathrm{~h}$ (gels a, c, e, g, i, and k, respectively). Coomassie blue stain of spectrin digests from membranes of C.G. at $0,2,5,15$, and 40 min and at $24 \mathrm{~h}$ (gels b, d, f, h, j, and l, respectively). (B) Autoradiograph of A. Gels a-l correspond to Coomassiestained digests in A. 
TABLE I

Phosphorylation of Band 2 and Casein by Normal and HE Membranes

\begin{tabular}{ccc}
\hline & \multicolumn{2}{c}{ 32P-Phosphate incorporated } \\
\cline { 2 - 3 } Subject & Band 2 & Casein \\
\hline & \multicolumn{2}{c}{ pmol/10 min/mg protein } \\
Control & \multicolumn{2}{c}{} \\
1 & 101 & 962 \\
2 & 97 & 890 \\
3 & 102 & 1,231 \\
4 & 75 & 1,109 \\
Mean \pm SD & $93 \pm 13$ & $1,048 \pm 152$ \\
HE (C.G.) & 49 & 1,764 \\
HE (T.M.) & 114 & 2,105 \\
\hline
\end{tabular}

Spectrin kinase and casein kinase activity of $H E$ membranes. Spectrin kinase activity and casein kinase activity of erythrocyte membranes from patients C.G. and T.M. and four control subjects are shown in Table I. Membranes of patient C.G. had markedly decreased spectrin kinase activity, whereas that of patient T.M. showed normal activity. Casein kinase activity of erythrocyte membranes of both C.G. and T.M. was increased compared with control membranes.

Spectrin extractability of HE membranes. Extractability of spectrin $\left(4^{\circ} \mathrm{C}\right.$ for $\left.48 \mathrm{~h}\right)$ from erythrocyte membranes of patients C.G. and T.M. was 79 and $71 \%$, respectively, compared with values of 67 and $76 \%$ in two controls.

\section{DISCUSSION}

The major finding in this study is the demonstration of a structural abnormality in spectrin in one of four patients with different variants of $\mathrm{HE}$. We postulate that this change in the spectrin molecule affects its interaction with other cytoskeletal proteins and is responsible for the abnormal deformability of these erythrocytes and their predisposition to hemolysis. The three patients with HE who do not show any abnormality of spectrin on tryptic digestion-viz., subjects T.M., R.L., and J.E. - can be classified respectively as mild HE with transient poikilocytosis and pyknocytosis in infancy, mild HE with sporadic hemolysis, and mild HE without hemolysis. However, the fourth patient, C.G., does present problems in classification into one of the six categories of HE described by Lux and Wolfe (1). The morphology of her erythrocytes is predominantly elliptocytic, she has an ongoing hemolytic anemia that has responded to but not been cured by splenectomy, and she has grossly increased osmotic fragility and autohemolysis. She clearly does not fall into the sporadic hemolysis variant of mild HE, and although these features might be consistent with homozygous $\mathrm{HE}$, neither parent shows any morphological abnormality of his or her erythrocytes. The marked fragmentation of erythrocytes at $45^{\circ} \mathrm{C}$ also poses the question of relationship to the HPP syndrome. Although no firm diagnostic criteria have been established for HPP (14), the progressive fragmentation and sphering on heating her erythrocytes to $49^{\circ} \mathrm{C}$, as well as the normal mean corpuscular volume, militate against this diagnosis.

In subject C.G., the series of large polypeptide fragments generated on tryptic digestion of spectrin at low salt concentration in unfractionated extracts obtained at either $4^{\circ}$ or $37^{\circ} \mathrm{C}$ or of column-purified spectrin is distinctly different from that seen in the control (Fig. 3). These differences are seen at all times of digestion tested from $2 \mathrm{~min}$ to $24 \mathrm{~h}$. Furthermore, the initial rate of digestion of band 2 is decreased compared with the control. This is particularly well seen at 2 and $5 \mathrm{~min}$ (Fig. 3, gels $d$ and $f$ ), a finding that is further supported by the slower rate of loss of ${ }^{32} \mathrm{P}$ on tryptic digestion of ${ }^{32} \mathrm{P}$ labeled band 2 (Fig. 6). Another striking feature of the tryptic digests of spectrin from C.G. is the relative paucity of fragments below a molecular weight of $\sim 126,000$, whereas such fragments are a constant feature of control digestions, and are found down to a molecular weight of $\sim 54,000$ (Fig. 3, gels $i$ and $k$ ). Tryptic digests of C.G.'s spectrin at physiological salt concentration $(150 \mathrm{mM}$ $\mathrm{NH}_{4} \mathrm{HCO}_{3}$ ), although qualitatively similar to controls, show marked quantitative differences, with an increased susceptibility of both bands 1 and 2 to tryptic digestion at times up to $40 \mathrm{~min}$ (Fig. 5). At $24 \mathrm{~h}$, the tryptic digests of both C.G. and the control are identical.

The altered qualitative pattern of the remaining polypeptides after tryptic digestion at low ionic strength of spectrin obtained from erythrocytes of C.G., as well as the slower rate of loss of ${ }^{32} \mathrm{P}$ from labeled band 2 , is strong evidence that this spectrin has an altered accessibility to trypsin. It is important to note that spectrin is a flexible molecule with little conformational stability, and appears to consist of rigid, possibly globular elements, linked by random, flexible sections of polypeptide chain, which may allow the molecule to expand considerably at low ionic strength (15). The marked differences in the structure of C.G.'s spectrin, as reflected in the abnormal susceptibility to tryptic digestion at low ionic strength, could be explained in several ways. There could be an altered placement of arginine and lysine residues within the spectrin molecule. Alternatively, some other sequence abnormality could affect the folded structure of spectrin and its conformational stability at low ionic strength. A further possibility is a post-translational modification of C.G.'s spectrin molecules, which could affect susceptibility to tryptic digestion. Differences in the conformation of the molecule apply also to spectrin as it exists in C.G.'s erythrocytes, since there is a markedly increased susceptibility to tryptic digestion at physiological salt concentrations of 
spectrin extracted at $4^{\circ} \mathrm{C}$ and in a native tetrameric form. The possibility of altered placement of arginine and lysine residues is unlikely, however, as the qualitative pattern of the tryptic digests at high ionic strength is the same as the control. We suggest that the native membrane spectrin of C.G. is abnormal, but at present we cannot distinguish whether this is a primary or secondary abnormality, and we also suggest that this molecule could exhibit deceased conformational stability on exposure to low ionic strength, with the generation of a qualitatively abnormal tryptic digest pattern. Preliminary observations support our contention of an abnormality of C.G.'s spectrin, as dimer-tetramer and tetramer-dimer interconversions of her spectrin at physiological ionic strength are grossly abnormal (Coetzer and Zail, unpublished observations).

Additional support for an abnormality of spectrin in C.G. is the finding of decreased spectrin kinase activity of her erythrocyte membranes in the presence of intact phosphorylation of a phosphoprotein such as casein (Table I). These results are similar to those of Walter et al. (3) in a study of HPP spectrin and suggest that an abnormally folded spectrin molecule could limit access to phosphorylation by membrane spectrin kinase. In this regard note that the spectrin kinase assay is performed at low salt concentration, which could lead to conformational instability of C.G.'s spectrin, whereas phosphorylation of spectrin in her intact erythrocytes appears to be normal.

Additional evidence for an abnormality of spectrin or its interaction with erythrocyte membranes was sought by determining spectrin extractability by prolonged dialysis of fresh membranes against a low ionic strength buffer at $0^{\circ} \mathrm{C}$. This approach was prompted by the recent demonstration of abnormal extractability of spectrin from erythrocyte membranes in a minority of patients with hereditary spherocytosis (16). In any event, we could not demonstrate any alteration in spectrin extractability in either of two of the subjects (C.G. and T.M.) with HE.

The findings in the other three patients with variants of $\mathrm{HE}$ are of some importance. Although T.M. shows the striking morphological abnormalities characteristic of mild $\mathrm{HE}$ with poikilocytosis and pyknocytosis in infants upon heating his erythrocytes to $45^{\circ} \mathrm{C}$ (Fig. 1), no abnormalities could be detected after tryptic digestion of labeled and unlabeled spectrin extracts of his erythrocyte membranes, nor was spectrin kinase activity impaired. It is, however, possible that some other abnormality of spectrin could be present in this patient, which does not preclude normal accessibility to trypsin or normal ability to phosphorylate spectrin. Similar arguments apply to the other two patients who also had normal tryptic digests of whole spectrin extracts.

The appearance of a ${ }^{32} \mathrm{P}$-labeled tryptic fragment of molecular weight of $\sim 200,000$, in addition to band 2
$(215,000)$, in digests of C.G.'s spectrin (Fig. 6B) requires further discussion. Anderson (8) recently presented evidence that all phosphorylation sites on spectrin are within $8,000 \mathrm{~mol}$ wt of a terminal of band 2, whereas the studies of Harris et al. (17) indicate that the phosphorylation sites of spectrin labeled by incubation of intact erythrocytes with ${ }^{32} \mathrm{PO}_{4}$ are contained within two tryptic fragments of molecular weights of 17,200 and 2,400 near the C-terminal end of band 2 . The 17,200-mol wt fragment is a complex of a 4,600and a 3,500-mol wt peptide. If these fragments are contiguous, the phosphorylated sites could be as close as $5,900 \mathrm{~mol} w \mathrm{w}$ or as far as $10,500 \mathrm{~mol}$ wt from the Cterminus of band 2. If tryptic digestion occurred only at the phosphorylated (C-terminal) end of the molecule, this would indicate the presence of a phosphorylation site at a point from the C-terminus of C.G.'s spectrin greater than a fragment of molecular weight of $\sim 15,000$, assuming a molecular weight of 215,000 for band 2 . This labeled tryptic fragment does not, however, appear to be unique to patient C.G., in that a faintly labeled band is seen in the same position in the control spectrin preparation at $5 \mathrm{~min}$ (Fig. $6 \mathrm{~B}$, gel e). A more likely explanation is that, if tryptic fragments are generated from the nonphosphorylated ( $N$-terminal) end of band 2 in C.G.'s spectrin, phosphorylated forms of almost any molecular weight could occur with the phosphates located in their correct position. In either event both labeled tryptic peptides of C.G.'s spectrin are discernible at times when the label is absent from the control spectrin preparation.

\section{ACKNOWLEDGMENTS}

We are indebted to Dr. L. Macdougall for permission to study her patient.

This study was supported by grants from the Atomic Energy Board and the Medical Research Council of South Africa.

\section{REFERENCES}

1. Lux, S. E., and L. C. Wolfe. 1980. Inherited disorders of the red cell membrane skeleton. Pediatr. Clin. N. Am. 27: 463-486.

2. Lux, S. E. 1979. Spectrin actin membrane skeleton of normal and abnormal red blood cells. Semin. Haematol. 16: $21-51$.

3. Walter, T., W. Mentzer, A. Greenquist, S. Schrier, and N. Mohandas. 1977. RBC membrane abnormalities in hereditary pyropoikilocytosis. Blood. 50(Suppl. 1): 98.

4. Chang, K., J. R. Williamson, and H. S. Zarkowsky. 1979. Altered circular dichroism of spectrin in hereditary pyropoikilocytosis. J. Clin. Invest. 64: 326-328.

5. Gomperts, E. D., F. Cayanis, J. Metz, and S. Zail. 1973. A red cell protein abnormality in hereditary elliptocytosis. Br. J. Haematol. 25: 415-420.

6. Coetzer, T., and S. S. Zail. 1979. Erythrocyte membrane proteins in hereditary glucosephosphate isomerase deficiency. J. Clin. Invest. 63: 552-561.

7. Bennett, V., and D. Branton. 1977. Selective association of spectrin with the cytoplasmic surface of human 
erythrocyte plasma membranes.J. Biol. Chem. 252: 27532763.

8. Anderson, J. M. 1979. Structural studies on human spectrin. Comparison of subunits and fragmentation of native spectrin. J. Biol. Chem. 254: 939-944.

9. Fairbanks, G., T. L. Steck, and D. F. H. Wallach. 1971. Electrophoretic analysis of the major polypeptides of the human erythrocyte membrane. Biochemistry. 10: 26022617.

10. Steck, T. L. 1974. The organization of proteins in the human red blood cell membrane. A review. J. Cell Biol. 62: $1-19$.

11. Lowry, O. H., N. J. Rosebrough, A. L. Farr, and R. J Randall. 1951. Protein measurement with the Folin phenol reagent. J. Biol. Chem. 193: 265-275.

12. Beutler, E., E. Guinto, and C. Johnson. 1976. Human red cell protein kinase in normal subjects and patients with hereditary spherocytosis, sickle cell disease, and autoimmune hemolytic anemia. Blood. 48: 887-898.

13. Corbin, J. D., and E. M. Reimann. 1974. Assay of cyclic AMP-dependent protein kinases. Methods Enzymol. 38 287-290.

14. Zarkowski, H. W., N. Mohandas, C. B. Speaker, and S. B. Shohet. 1975. A congenital haemolytic anaemia with thermal sensitivity of the erythrocyte membrane. $\mathrm{Br} . J$. Haematol. 29: 537-543.

15. Calvert, R., E. Ungewickell, and W. Gratzer. 1980. A conformational study of human spectrin. Eur. J. Biochem. 107: 363-367.

16. Sheehy, R., and G. B. Ralston. 1978. Abnormal binding of spectrin to the membrane and erythrocytes in some cases of hereditary spherocytosis. Blut. 36: 145-148.

17. Harris, H. W., Jr., N. Levin, and S. E. Lux. 1980. Structural and kinetic studies of spectrin phosphorylation in human red cells. Fed. Proc. 39: 2047. 